\title{
Evaluation of Upper and Lower Lip Growth following Cronin Method Labioplasty in Unilateral Complete Cleft Lip and Palate Cases
}

\author{
Made Widya Utami ${ }^{1}$, Muhammad Syafrudin Hak $^{2}$, Lilies Dwi Sulistyani ${ }^{3 *}$, \\ Pradono Suhardi ${ }^{3}$ \\ ${ }^{1}$ Oral and Maxillofacial Surgery Residency Program, Faculty of Dentistry, Universitas Indonesia \\ Indonesia \\ ${ }^{2}$ Division of Oral and Maxillofacial Surgery, Cleft Lip and Palate Unit, Anak dan Bunda \\ Harapan Kita Hospital, Indonesia \\ ${ }^{3}$ Department of Oral and Maxillofacial Surgery, Faculty of Dentistry, Universitas Indonesia, \\ Indonesia \\ *Email: liliesdwi_s@yahoo.co.id
}

\begin{abstract}
The importance of lips in influencing facial profile quality is now a major consideration in the surgical treatment of patients with cleft lips. Orbicularis oris reconstruction is important in the Cronin method of labioplasty in order to balance upper lip growth. This study evaluates upper- and lower lip growth following Cronin method labioplasty in patients with unilateral cleft lip and palate (UCLP) based on the protocol of the Cleft Center Harapan Kita General Hospital. After undergoing the Cronin method of labioplasty, 36 patients with UCLP were photographed on the anterior and lateral sides using a standardized method at ages 1 and 2 years. The upper and lower lips were measured and compared. At 1 year of age, the lower lip height and vermillion length were slightly lesser than the upper lip height and vermillion length. At 2 years of age, the lower lip height and vermillion length were slightly lesser than the upper lip height and vermillion length. The lower lip was $94 \%-95 \%$ as large as the upper lip. Based on anthropometric measurements, the vertical height and vermillion length of the upper and lower lips in UCLP cases increases with age after following Cronin method of labioplasty.
\end{abstract}

Keywords: Cleft lip, cleft palate, Cronin method labioplasty, lip symmetry, anthropometry

\section{Introduction}

Cleft lip and palate are the most common congenital anomalies of the oral and maxillofacial region. Approximately $90 \%$ of all cleft lip cases are unilateral [1]. Labial defects typically involve discontinuity of the circumoral musculature and reduced lip muscle volume in patients with cleft lips [2]. The lips play an important role in facial expressions, speech, and mastication [3]. The shape of the Cupid's bow and the lip's length and projection may be considered indicators of youth, health, and attractiveness [4]. 
Facial anthropometric studies have often been used in anthropology and the medical field since the 20th century. These studies have been used in the diagnosis, treatment planning, and evaluation of congenital abnormalities [5]. Many common definitions have used facial anthropometric landmark measurements by Farkas since 1971. Indirect anthropometric techniques that use standardized photographs have several advantages over direct anthropometric techniques, among other noninvasive lip measurement methods: it is easier to take measurements because the subject is stationary, which prevents errors due to skin compression when directly measured; measurements can be repeated; data can be stored permanently; and it is easier to compare test results from before and after labioplasty [6].

In 1959, R.O. Brauer and Cronin noticed that by using all methods, the lip cleft side had a tendency to vertically be very long, which continues to increase as the child grows. In 1966, Cronin introduced labioplasty, a modification of the Tennison method (1952), for cases of unilateral cleft lip and palate (UCLP) that use muscle management in order to maintain Cupid's bow integrity, minimize healthy tissue removal, and produce symmetrical lips with minimal scarring [7]. The Cleft Center Harapan Kita General Hospital has developed an integrated UCLP management procedure including multidisciplinary professions to achieve optimal labioplasty. Labioplasty procedures performed at the Cleft Center Harapan Kita General Hospital employ the Cronin method.

\section{Methods}

The present study was conducted at the Cleft Center Harapan Kita General Hospital from March to May 2016. Sample data were selected from the records of patients with UCLP at the Cleft Center Harapan Kita General Hospital from 2015 to 2016 who underwent the Cronin method of labioplasty. The subjects were selected on the basis of certain inclusion and exclusion criteria. The criteria for inclusion in this study were UCLP cases who had undergone the Cronin method of labioplasty, nonsyndromic UCLP cases aged $<1$ year at the time surgery, and willingness to take part in the study and provide informed consent. The subjects who did not periodically follow up and those with tissue dehiscence in the lip region were excluded from the study.

Thirty-six patients with UCLP were photographed using a standardized method on the anterior and lateral sides at 1 and 2 years of age, having undergone the Cronin method of labioplasty. The upper and lower lips were measured and compared. All the data were processed using the SPSS 22.0 statistical software (Chicago, IL, USA). Anthropometric measurement is a method that uses anatomicalspecific soft-tissue landmarks. A landmark in this study refers to the points introduced by Leslie G. Farkas. Landmark distance-measured items were as follows in Fig 1. 

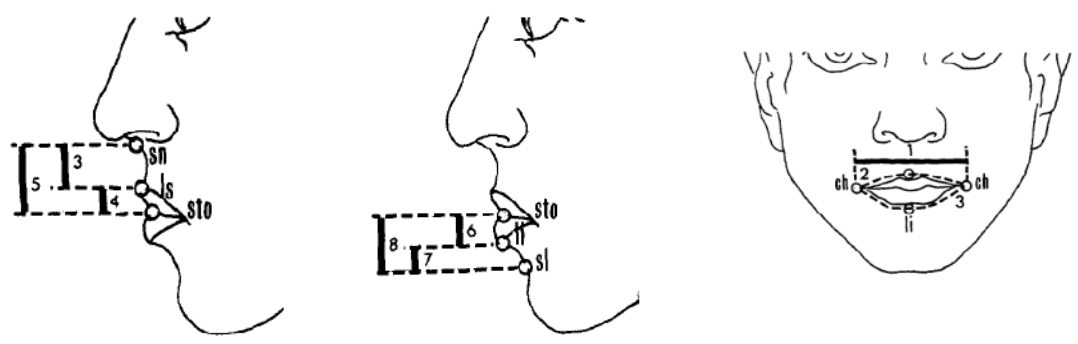

Fig 1. B3 = height of the cutaneous upper lip (subnasale-labialesuperius, snIs), B4 = height of the upper vermillion (labialesuperius-stomion, Is-sto), B5 = height of the upper lip (subnasale-stomion, sn sto), C6 = height of the lower vermillion (stomion-labialeinferius, sto-li), $\mathrm{C} 7=$ height of the cutaneous lower lip (labialeinferius-sublabiale, li-sl), C8 = median vertical height of the lower lip (stomion-sublabiale, sto-sl), D1 = length of the labial fissure (cheilion-cheilion, ch-ch), D2 = length of upper vermillion arcs (cheilion-labialesuperius-cheilion, ch-Is-ch), and D3 = length of lower vermillion arcs (cheilion-labialeinferius-

cheilion, ch-li-ch) [6].

\section{Results}

The average upper and lower vertical height and vermillion surface arc values in patients with UCLP following Cronin method labioplasty increase with age, as indicated. The lower lip height $(4.84 \pm 0.98)$ and vermillion length $(33.29 \pm 3.95)$ was slightly lesser than the upper lip height $(5.69 \pm 1.37)$ and vermillion length $(35.22 \pm 5.65)$ at the 1 year of age. The lower lip height $(5.69 \pm 0.89)$ and vermillion length $(36.03 \pm 5.07)$ was slightly lesser than the upper lip height $(6.39 \pm$ $1.50)$ and vermillion length $(38.16 \pm 5.87)$ at 2 years of age. On average, the lower lip was $94 \%-95 \%$ as large as the upper lip.

In 1984, Farkas conducted anthropometric lip measurements and obtained average vertical lip height and vermillion surface arc values in normal Caucasians aged 1-25 years [6]. Of all the nine variables measured, only the height of the upper vermillion (Is-sto) in one and two-year-olds (5.69 $\pm 1: 37$ and 6:39 $\pm 1: 50$, respectively) in UCLP cases following Cronin method labioplasty had higher values than those in normal one and two-year-olds (5.4 \pm 0.9 and $5.9 \pm 1.2$, respectively) based on Farkas' anthropometric data, whereas the other data, such as cutaneous vertical height, median vertical upper and lower lip heights, lower vermillion heights, and vermillion surface arcs in patients that underwent Cronin method labioplasty at 1 and 2 years of age exhibited lower values than those exhibited by normal subjects of the same age. 


\section{Discussion}

Lip morphology plays an important role in patients with UCLP, particularly when reconstruction is performed. The vertical height of the upper and lower lips as well as mouth length can help to evaluate changes in the vertical direction corresponding to changes in the transverse direction of the mouth length. [8] Vermillion and cutaneous upper and lower lips are helpful in evaluating labioplasty results in patients with UCLP. Precise measurement is the key to successful UCLP repair [9].

In the present study, the average upper and lower vertical heights and vermillion surface arc values in patients with UCLP following Cronin method labioplasty increased with age. Lip height only increased by up to $2 \mathrm{~mm}$, whereas lip width increased by up to $12 \mathrm{~mm}$ in subjects aged $2-12$ years. Within one year, the lip height reached $80 \%$ of the adult lip size in both males and females. The lip growth height between 1 and 2 years of age is important for lip growth in adulthood [10].

Generally, one third of the upper lip is composed of vermillion, and the remaining two thirds is composed of the cutaneous part, whereas almost half of the lower lip is composed of vermillion and the rest is composed of the surrounding skin [6]. The present study found that the lower lip height was lower than that of the upper lip in both males and females. The cutaneous height of the upper lip and nose width at 1 year of age showed the highest level of development $(80.2 \%$ and $79.5 \%$ respectively) when compared with that of adults. The highest lip growth occurs between 1 and 5 years of age [6].

\section{Conclusion}

The vertical height and vermillion length of the upper and lower lips in UCLP cases following Cronin method labioplasty based on the anthropometric measurements with standardized photographs increase with age.

\section{References}

1. Cobourne MT, editor. Cleft Lip and Palate. Karger Medical and Scientific Publishers; 2012 .

2. Nicolau PJ. The orbicularis oris muscle: a functional approach to its repair in the cleft lip. Br J Plastic Surg. 1983;36(2):141-53.

3. Tamada I, Nakajima T. Detailed assessment of cleft lip scar following straight line repair. J Plastic, Reconstructive Aesthetic Surg. 2010;63(2):282-8.

4. Shprintzen RJ, Bardach J. Cleft palate speech management: a multidisciplinary approach. Mosby Incorporated; 1995.

5. Han K, Kwon HJ, Choi TH, Kim JH, Son D. Comparison of anthropometry with photogrammetry based on a standardized clinical photographic technique using a cephalostat and chair. J Cranio-Maxillofac Surg. 2010;38(2):96-107.

6. Farkas LG, Katic MJ, Hreczko TA, Deutsch C, Munro IR. Anthropometric Proportions in The Upper Lip-Lower Lip-Chin Area of The Lower Face in Young White Adults. Am J Orthod. 1984;86(1):52-60.

7. Cronin TD. A modification of the Tennison-type lip repair. Cleft Palate J. 1966; 3:37682.

8. Bilwatsch S, Kramer M, Haeusler G, Schuster M, Wurm J, Vairaktaris E, Neukam FW, Nkenke E. Nasolabial symmetry following Tennison-Randall lip repair: a three- 
dimensional approach in 10-year-old patients with unilateral clefts of lip, alveolus and palate. J Cranio-Maxillofac Surg. 2006;34(5):253-62.

9. Chou PY, Luo CC, Chen PK, Chen YR, Noordhoff MS, Lo LJ. Preoperative lip measurement in patients with complete unilateral cleft lip/palate and its comparison with norms. J Plastic, Reconstructive Aesthetic Surg. 2013;66(4):513-7.

10. Zhu LY, Meng T, Shi B, Deng DZ. Anthropometric study of the upper lip of 1500 healthy children in Chengdu, Western China. $\mathrm{Br} J$ Oral Maxillofac Surg. 2008;46(7):554-60. 